\title{
Implementation of a Group Cutting Scheme during Processing of Large-Module Gears with a Prefabricated Tool
}

\author{
E.V. Artamonov ${ }^{1}$, V.V. Kireev ${ }^{1}$, and V.A. Zyryanov ${ }^{1, *}$ \\ ${ }^{1}$ Tyumen industrial university, Tyumen, Russian Federation
}

\begin{abstract}
Currently, when machining gears, the main problem arises - the resistance of a standard worm mill. In the current conditions of sanctions, import substitution and the launch of the State program for the development of its own metal cutting tool designs by tool companies, the creation of prefabricated structures can be considered a promising and effective solution, since this has been repeatedly confirmed by leading Russian researchers [1-8].
\end{abstract}

In the work, the possibility of creating prefabricated worm cutters with replaceable cutting hard alloy plates for rough processing of large-module gears is considered. Gears have entered our daily life everywhere, their range of applications is very wide. For the Tyumen region, which is the leading oil and gas and oil producing region of Russia, the need for processing gears is very large, since they are used in all technological installations.

There are many methods of processing gears, but let us dwell on the method of rolling using worm cutters. Tool companies in the Russian Federation today do not offer designs of prefabricated worm cutters for processing large-module gears capable of providing the required performance, high productivity and economic efficiency in toothfreasing. Also, the design of the tool and its cutting elements must withstand high transient loads and stresses arising during processing.

You must start with the placement of replaceable cutting hard-alloy elements in the initial outline of the tool rack. As an example, consider the initial outline of the tool rack for gears with module $\mathrm{m}=14$. In accordance with GOST 13755-81, we carry out mathematical calculation and construction of the initial outline of the tool rack in the Kompas-3D software (Fig. 1). Then we proceed to arrangement of replaceable cutting hard-alloy plates in initial contour of tool rack. As mentioned above, the toothfreasing process is complex and imposes high demands on the tool.

\footnotetext{
* Corresponding author: macho_9208@mail.ru
} 


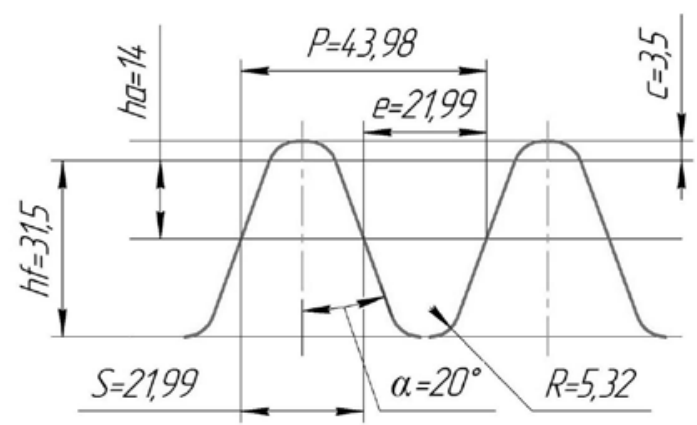

Fig. 1. The initial outline of the tool rail for $\mathrm{m}=14$

Based on this, in the design of the tool it is necessary to use RHACB of a shape that can withstand high transient loads and not collapse. After the information search, attention was drawn to the work [9], which sets out the classification of RHACB in the areas of functional efficiency: improving the strength and accuracy of positioning (Fig.2).

The author speaks of the need to use cutting elements with a maximum angle at the vertex $\varepsilon$.

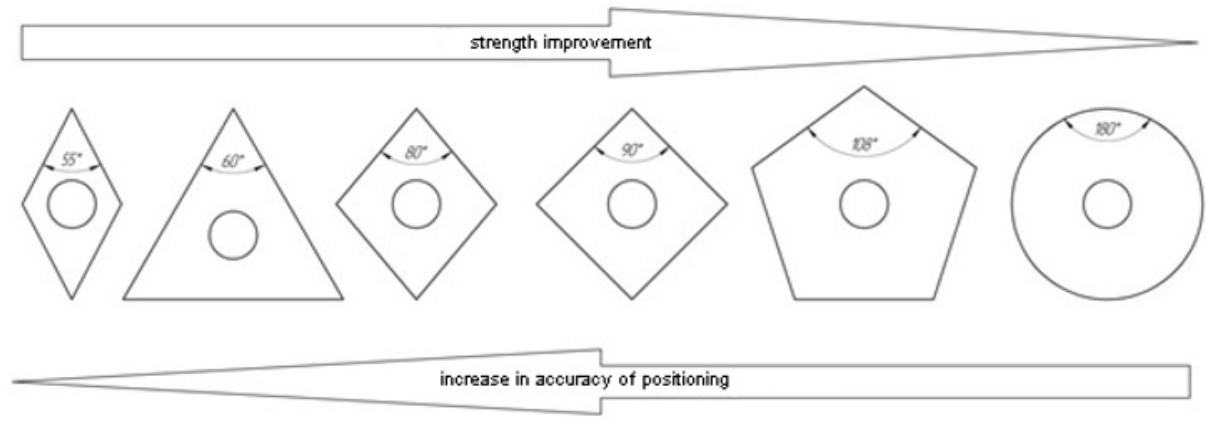

Fig. 2. Classification of RHACB forms

Therefore, as an example, take the 5-faceted plate and arrange it in the initial contour of the tool rack (Fig. 3).

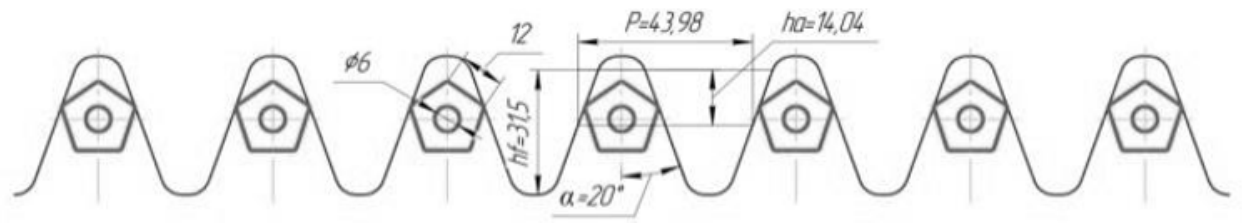

Fig. 3. Diagram of location of 5-sided RHACB in the initial contour of instrument rack

In the same way, we place a round RHACB - plate of maximum strength (Fig. 4).

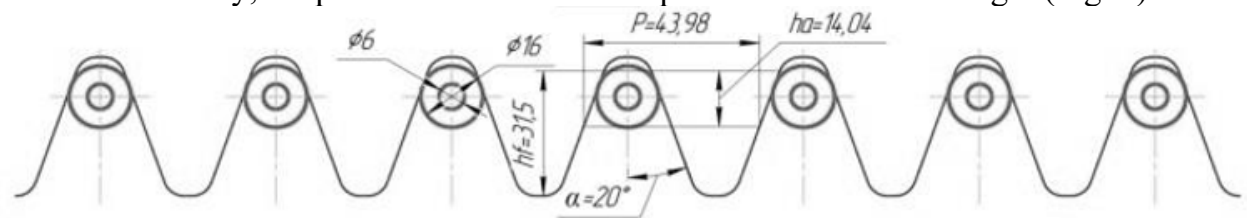

Fig. 4. Arrangement diagram of round RHACB in the initial contour of the tool rack 
However, these RHACB layout patterns on the tool rack have disadvantages. After machining with a tool with a similar arrangement of cutting elements in the tool body, further machining with large values of the shear layer and a workpiece will be required. If we talk about a round plate with an angle $\mathrm{a}=180^{\circ}$, then it is quite difficult to attach it in the tool body. Therefore, the way out of this situation is the use of cutters with a new, more advanced cutting scheme.

In search of solutions [10-15] for creation of fundamentally new tool, and selection of optimal method of attachment of cutting hard-alloy plates, modification of tool and reduction of loads in process of tooth cutting, results of studies in work [16] deserve attention. It suggests the idea of arranging the cutting elements in the tool body tangentially. Works [17-18] proposed a combined arrangement of RHACB in the tool body. This arrangement of cutting elements in the body of the dental tool is called group. The group circuit is implemented by sequential cutting of the allowance for processing of the RHACB gear blank with the main elliptical, radially located and side tangentially located plates. This divides the chips into simpler elements by sequentially cutting the machining allowance (Fig. 5).
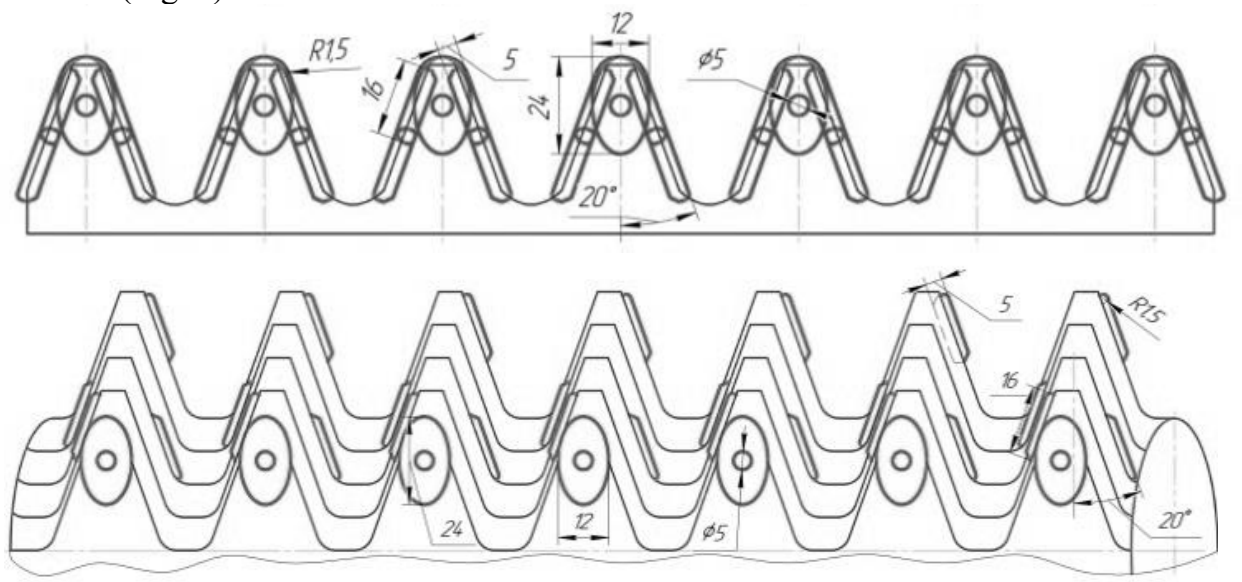

Fig. 5. Group layout of RHACB fitting in the initial contour of tool rack

In works [19-20], studies were carried out to determine the cross-sectional areas of the cut layer and the boundary loading conditions of the cutting elements. This enabled the ANSYS software to determine the resulting principal stresses during machining.

Analysis of the obtained pictures of the main stress distribution isolines showed that the maximum tension stress at the base of the tooth of the standard worm cutter reaches about $1355 \mathrm{MPa}$, which is 2.6 times more than the replaceable cutting element of the elipse shape installed in the design of the assembled worm cutter with a group arrangement of cutting elements (Fig. 6).

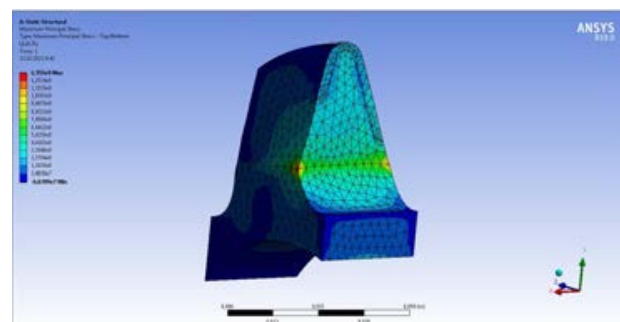

Standard worm cutter tooth

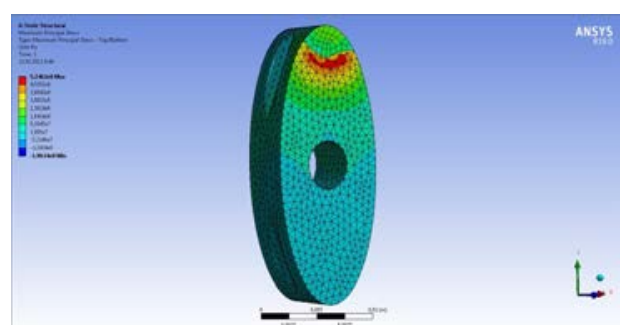

Elliptical Milling Mill Feature

Fig. 6. Main stress distribution patterns for the standard worm cutter tooth and the Elipse tool cutter 
The greatest tensile stress values of $\alpha 1$ are observed at the tooth base on the front surface of the standard worm cutter, which correlates well with the stress distribution in the cantilever pinched beam. As for the tension values in the contact zone and beyond the contact zone, their values range from 610 to $800 \mathrm{MPa}$ on the front surface of the tooth from 0 to $30 \mathrm{~mm}$. For the elliptical element of the assembled worm cutter, the maximum tensile stresses reach their maximum of $500 \mathrm{MPa}$ outside the contact zone at a distance of 2 to 5 $\mathrm{mm}$ from the apex.

This type of stress distribution is explained by the fact that due to the implementation of the group cutting circuit, the allowance for processing the tooth groove of the wheel is sequentially cut by separate cutting elements located both radially and tangentially [21]. Also, the use of an elliptical plate with an increased apex angle [epsilon] as compared to the tooth of a standard worm cutter allows reducing the dangerous stresses [epsilon] 1 by 2-2.5 times and, therefore, increasing the strength of the cutting insert. Thus, the processing of gears in the implementation of the group cutting scheme by using prefabricated worm cutters with replaceable cutting hard-alloy plates compared to the operation of a standard worm cutter made of high-speed steel makes it possible to significantly reduce tensile stresses on the front surface, increase the cutting speed and, accordingly, increase the operability and processing efficiency.

\section{References}

1. Grechishnikov V.A., Grigoriev S.N., Maslov A.R., Schirtladze A.G., Instrumentation of integrated engineering plants. Thin Knowledge-Intensive Technologies LLC. Staryj Oskol, 2018g.

2. Semenchenko I. I., Matyushin V. M., Sakharov G. N., Designing metal cutting tools. M.: Mechanical engineering, 1963. $952 \mathrm{~s}$.

3. Boriskin O. I., Stakhanov N. G., Yakushenkov A. V., Involute worm cutter with hardalloy racks. Domestic and foreign experience of quality assurance in mechanical engineering: All-Russian scientific and technical conference. Tula, 2019g. pp. 116118.

4. Chulin I.V., Improvement of resistance of prefabricated hard alloy cutters for treatment of railway points. Dissertation of candidate of technical sciences. Moscow, $2011 \mathrm{~g}$.

5. Isaev A.V., Development of prefabricated cutters with replaceable polyhedral hard alloy plates located on the helical surface for processing of blanks with shaped profile. Dissertation of candidate of technical sciences. Moscow, 2012g.

6. Grechishnikov V.A., Isaev, A.V., Romanov V. B., Method of forming profile of generatrix of initial tool surface of prefabricated cutters with cutting plates located along screw line. Bulletin of MSTU Stankin. Moscow, 2015g. pp. 8-12.

7. Chevychelov S. A., Improved design efficiency of hyperbolic cutters by computer simulation of rail reprofiling process. Dissertation of candidate of technical sciences. Orel, 2005g.

8. Nichkov A.G., Bases of a complex research of process of gear milling and optimization of its design and process parameters in the simple and combined schemes of cutting of cogwheels worm mills. Dissertation of the Doctor of Engineering. Tula, 1991g.

9. Artamonov E.V. Durability and working capacity of retrofittable hard alloy blades of assembly cutting tools. - Tyumen': TyumGNGU, 2003. - 192 s. ISBN 5-88465-416-2 
10. Smirnov N.N., Gear milling by much screw worm mills with different schemes of cutting. Dissertation of candidate of technical sciences. Kiev, 1982g.

11. Medvedickov S.N., High-performance gear cutting by mills. M.: Mechanical engineering, 1981. $106 \mathrm{~s}$.

12. Srinivasan N., Shunmugam M. S., Limiting conditions in gear shaping for corrected involute gears. International Journal of Machine Tool Design and Research. v.23, Issue 4, 1983, pp. 227-235.

13. T. Tokawa, Y. Nishimura, Y. Nakamura, High productivity dry hobbing system, J. Mitsubishi Heavy Ind. v.38(1). pp. 27-31. (2001)

14. Papsheva N.D., Akushskaya O.M., Improving the efficiency of the process of gear cutting, Engineering journal of Don. 36 (2015) 54.

15. W. Liu, D. Ren, S. Usui, J. Wadell, T. D. Marusich, A gear cutting predictive model using the finite element method, J. CIRP. v.8 pp. 51-56. (2013)

16. Artamonov E.V., Pomigalova T.E., Tveryakov A.M., Uteshev M.Kh., Fracture mechanics and strength of replaceable hard alloy cutting inserts. Tyumen.: TyumGNSU, 2013. $148 \mathrm{~s}$.

17. Artamonov E.V., Kireev V.V., Zyryanov V.A., An interlocking side mill with retrofittable carbide blades for processing of coarse-pitch tooth wheels, MATEC Web of Conferences 224. ICMTMTE - 2018. pp. 1-5. (2018)

18. Artamonov E.V., Kireev V.V., Zyryanov V.A., Lay-out of cutting blades in an assembly basic rack of a counterpart rack for hob gears, IOP Conference Series: Materials Science and Engineering - 2019. pp. 1-6. (2019)

19. Artamonov E.V., Kireev V.V., Zyryanov V.A., Increase of efficiency of tooth cutting by creation of prefabricated cutters with replaceable cutting hard alloy plates. News of Southwestern State University. Kursk, 2020g. pp. 35-51.

20. Artamonov E.V., Kireev V.V., Zyryanov V.A., Application of the group scheme of cutting when processing coarse-grain cogwheels, IOP Conference Series: Materials Science and Engineering - 2020. pp. 1-5. (2020)

21. Artamonov E.V., Kireev V.V., Zyryanov V.A., Prefabricated worm cutter with group cutting scheme, Pat. 2720011 Russian Federation, MPK B23F21/16. Patent holder Federal State Budgetary Institution for Higher Education "Tyumen Industrial University", 2020g. 